\title{
Experimental results of 47-level switch-ladder multilevel inverter.
}

\begin{abstract}
This paper provides experimental results for a $2.5-\mathrm{kW} 47$-level prototype of the switch-ladder multilevel inverter including the following: input and output voltage and current waveforms under resistive and inductive loads, efficiency, total harmonic distortion, voltage stresses across the switches, behavior of the system under fault condition, and no-load power dissipation. The most important advantage of this inverter is that only four switches conduct in each interval in low frequency. This matter, beside the elimination of switching losses, has made this inverter an efficient choice with $97 \%$ peak efficiency. The ability to continue working with open-circuit modules is another advantage of the inverter. Furthermore, some important factors behind the unreliability and inefficiency of inverters have been improved, including the following: low duty cycle of conducting switches, staircase voltage stresses across switches with low-voltage steppes, line switching frequency results in low temperature of switches, possibility of removing low-pass filters, and independence to capacitors. The inverter is proposed to be an advantageous choice in low-voltage stand-alone photovoltaic applications.
\end{abstract}

Keyword: Multi-level inverter 